\title{
Getting informed consent from patients to take part in the clinical training of students: randomised trial of two strategies
}

\author{
Katarina Westberg, Niels Lynøe, Ann Lalos, Mats Löfgren, Mikael Sandlund
}

Medical Ethics, Umeå University, S-901 87 Umeå, Sweden

Katarina Westberg medical student

Niels Lynøe associate professor Department of Clinical Science, University Hospital of Northern Sweden, S-901 85 Umeå

Ann Lalos professor

Mats Löfgren associate professor Mikael Sandlund consultant Correspondence to: N Lynøe

niels.lynoe@

socmed.umu.se

BMJ 2001;323:488
A few studies have examined the empirical aspect of the ethics of clinical training, ${ }^{1-3}$ but no randomised study has compared different strategies for giving information to patients about clinical training. We conducted a randomised, double blind trial to determine whether advance written information leads patients attending gynaecology outpatient clinics to decline to take part in the clinical training of medical students.

\section{Methods and results}

We recruited 163 patients between March 1998 and March 1999, giving them a date for a future consultation. The patients were also randomly allocated to receive either advance written information (plus the standard procedure of the individual gynaecologist) or only the standard procedure of the individual gynaecologist when they arrived at the gynaecology clinic. The advance information stated that (a) the clinic was involved in the clinical training of medical students; (b) the training of future doctors depended on the participation of patients; $(c)$ the skill of the gynaecologist whom the patient would meet resulted from previous patients' participation in training; and (d) participation in the training was strictly voluntary. We obtained ethical approval from the regional research ethics committee in Umeå.

Of the 163 patients, 77 received advance information and 86 were allocated to the standard procedure of the individual doctor. Forty patients receiving advance information and 41 patients allocated to current procedure dropped out for various reasons (for example, the appointed time was inconvenient, they wanted to see a female gynaecologist, or they had already recovered by the consultation time). A questionnaire was completed by 71 of the remaining 82 patients immediately after the consultation. Thus 32 patients remained in the group receiving advance information and 39 in the group allocated to standard procedure.

The patients were not told of their participation in the trial until they had completed the questionnaire, which asked for their views on the information they had received about medical students being present and on the way they had been told of the option to decline to take part in the clinical training; it also asked about their

Patients' perception of information on participating in the clinical training of medical students, according to whether they received advance written information $(n=32)$ or were exposed only to the standard procedure of the gynaecologist $\left(n=39^{*}\right)$

\begin{tabular}{lccccccc} 
& \multicolumn{5}{c}{ Perceived quality of information } \\
\cline { 2 - 7 } & Good & $\begin{array}{c}\text { Rather } \\
\text { good }\end{array}$ & $\begin{array}{c}\text { Rather } \\
\text { poor }\end{array}$ & Poor & $\begin{array}{c}\text { Received no } \\
\text { information }\end{array}$ & $\begin{array}{c}\text { Cannot } \\
\text { recall }\end{array}$ \\
\hline $\begin{array}{l}\text { Patients who received advance } \\
\text { written information }\end{array}$ & 27 & 5 & 0 & 0 & 0 & 0 \\
\hline $\begin{array}{l}\text { Patients who were exposed only to } \\
\text { standard procedure }\end{array}$ & 19 & 5 & 1 & 2 & 9 & 2 \\
\hline${ }^{*}$ One patient did not respond to this question. & & & & & & \\
\hline
\end{tabular}

motives for permitting a student to attend the consultation. The doctors and students were unaware of whether their patients had received advance information.

None of the 71 patients declined to participate in the clinical training of medical students; therefore whether they had been informed in advance had no effect on their decision to participate. Generally, most patients said they felt positive in principle about having students present during the consultation and the pelvic examination. Nine patients (two in the group who received advance information and seven in the group allocated to standard procedure), however, felt negative about this. One patient in the group who received advance information stated that she wished to be alone with the doctor on this occasion, compared with eight patients in the other group (Fisher's exact test, $\mathrm{P}=0.035$ ).

Patients who had received advance information perceived the information as good or rather good, whereas nine patients in the group allocated to current procedure stated that they had not been informed at all (table).

Most patients (55/71) said that they "felt free" to decline to participate in the clinical training. Of the 16 patients who did not feel free, four were in the group who had received advance information and 12 in the group allocated to current procedure. Feeling free when asked to participate in the clinical training seems to be significant $\left(\chi^{2}\right.$ test, $\left.\mathrm{P}=0.002\right)$.

\section{Comments}

The strategy on giving advance written information did not jeopardise or negatively affect the patients' inclination to participate in the clinical training of medical students. Arguments for not informing patients in advance seem to be based more on prejudice than on empirical evidence. Furthermore, if the training doctor adopted a policy of always giving patients advance written information, this might act as a model for students and thus for future doctors.

Contributors: KW helped to design and monitor the study and collected data. She also presented the first analysis and draft of the paper. NL helped to formulate the research hypothesis and design the study. He was also responsible for the analysis and for writing the paper. AL helped with the design and analysis and contributed to the writing and editing of the paper. ML helped to formulate the research hypothesis and design the study. He also helped with the analysis and contributed to the writing of the paper. MS helped to write and edit the paper.

Funding: This study received support through a grant from the Swedish Council for Social Research (grant No 97-0074).

Competing interests: None declared.

1 Lynoe N, Sandlund M, Westberg K, Duchek M. Informed consent in clinical training - patients' experiences and attitudes. Med Educ 1998;32: 465-71.

2 Lynoe N, Sandlund M. Ethical and educational aspects of clinical training-a study in the experience and attitudes of medical students. Scand J Soc Med 1995;23:216-9.

3 O'Flynn N, Spencer J, Jones R. Consent and confidentiality in teaching in general practice: survey of patients' views on presence of students. $B M J$ 1997;315:1142.

(Accepted 25 June 2001) 


\section{Drug points}

\section{Hypersensitivity reaction to balsalazide}

V Adhiyaman, A Vaishnavi, S Froese, Withybush General Hospital, Haverfordwest, Pembrokeshire SA61 2PZ

Balsalazide is used in short term and maintenance treatment of ulcerative colitis. It is a prodrug in which 5 -aminosalicylic acid is linked via a diazo bond to 4 -aminobenzoyl- $\beta$-alanine, an inert and biologically inactive carrier molecule. We report a case of a hypersensitivity reaction to balsalazide, involving pericarditis, an abnormal liver biochemistry profile, and splinter haemorrhages.

A 59 year old woman developed indeterminate patchy pancolitis. She was unable to take mesalazine or olsalazine but had no adverse effects with sulfasalazine $1 \mathrm{~g}$ twice daily, which she took as maintenance treatment. Eight months later her symptoms had resolved and she had normal results for inflammatory markers. On request sulfasalazine was discontinued and she started balsalazide $2.25 \mathrm{~g}$ three times daily.

Eight days later she was admitted with central chest pain, shortness of breath, and back pain, which gradually worsened over three days. The colitis was still in remission. On examination she was apyrexial, had splinter haemorrhages on two fingernails, and had a raised jugular venous pressure. She had a loud pericardial rub, but there were no murmurs, and the lungs were clear. A soft tender liver was just palpable. Optic fundi were normal.

Investigations showed grossly increased values for inflammatory markers (erythrocyte sedimentation rate 122 $\mathrm{mm}$ for first hour, $\mathrm{C}$ reactive protein concentration 251 $\mathrm{mg} / \mathrm{l}$ ) with a mild normocytic anaemia and thrombocytosis. A liver biochemistry profile was indicative of cholestasis (alkaline phosphatase $472 \mathrm{IU} / 1, \gamma$-glutamyl transferase 295 IU/1, alanine aminotransferase $50 \mathrm{U} / 1$, and bilirubin 15 $\mu \mathrm{mol} / 1)$. An electrocardiogram was suggestive of pericarditis, and an echocardiogram showed a small pericardial effusion. Ultrasonography of the liver and biliary tree was unremarkable. Multiple blood cultures and paired viral serology gave negative results. Results for autoantibodies including antinuclear factor, cytoskeletal antibodies, and antineutrophil cytoplasm antibody were negative.

Balsalazide was stopped while the results of investigations to exclude an infective or autoimmune cause were awaited. The patient was given non-steroidal antiinflammatory drugs, with some improvement of symptoms and reduction in concentration of acute phase reactants. The chest pain and pericardial rub persisted, however, and she was given prednisolone $20 \mathrm{mg}$ once daily, reduced by $5 \mathrm{mg}$ fortnightly. Symptoms and abnormal blood test results completely resolved within a month, and the steroids were discontinued.

Sulfasalazine was successfully reintroduced, and the patient has remained well. We believe the acute pericarditis, cholestatic liver biochemistry profile, and vasculitis resulted from hypersensitivity to balsalazide because the symptoms developed acutely and other causes were excluded by appropriate tests.

We believe this is the first report of a hypersensitivity reaction to balsalazide: the Committee on Safety of Medicines has received no such notifications, and a search of Medline (1990-9) revealed no cases.

This case has similarities to those of mesalazine associated pericarditis, ${ }^{1}$ pericardial effusion, ${ }^{2}$ and lupuslike syndrome. ${ }^{3}$ Pericarditis associated with sulfasalazine induced lupus syndrome has been recognised ${ }^{45}$ and was previously ascribed to the sulfapyridine moiety. However, similar reactions with 5-acetylsalicylic acid drugs such as mesalazine, which do not contain the sulfa group, suggest that an adverse reaction may be a consequence of the 5-acetylsalicylic acid molecule. Because the patient reacted to balsalazide but not sulfasalazine the hypersensitivity reaction may have been to the whole drug rather than the sulfapyridine moiety alone.

1 Habal FM, Greenberg GR. Treatment of ulcerative colitis with oral 5-ASA including patients with adverse reactions to sulphasalazine. Am J Gastroenterol 1990;83:15-9.

2 Jenss H, Becker EW, Weber P. Pericardial effusion during treatment with 5-aminosalicylic acid in a patient with Crohn's disease. Am J Gastroenterol 1990;85:332-3.

3 Dent MT, Ganapathy S, Holdsworth CD, Channer KC. Mesalazine induced lupus-like syndrome. BMJ 1992;305:159.

4 Griffiths ID, Kane SP. Sulphasalazine induced lupus syndrome in ulcerative colitis. BMJ 1977;ii:1188-9.

5 Deboever G, Devogelaere R, Holvoet G. Sulphasalazine induced lupus like syndrome with cardiac tamponade in a patient with ulcerative colitis. Am J Gastroenterol 1989;84:85-6.

\section{A patient who changed my practice \\ To tell or not to tell}

Whether it is correct to tell an elderly person how long he or she can expect to live, that is the question. In 50 years of work with elderly people, I have found it necessary only once to tell a patient that his expectation of life was short.

On my ward round I found a 72 year old man with a diagnosis of a large fungating carcinoma of the stomach busily engaged at the bedside with his bed covered in bits of paper bearing names and addresses. In reply to my inquiry as to what he was doing he said: "Doctor, I am planning to get married in two weeks' time and these are my wedding guests' invitations."

In privacy I explained in as kind a way as I could that he had a serious, life threatening disease and that it would be wise for him to put all his affairs in order and not to make any radical plans for the future. A moment's silence followed, and then, to my surprise, he stood up and shook my hand warmly and said: "Thank you very much for telling me all this, doctor, but you must excuse me as I have a lot of invitations to send out about my wedding." With that he hurried back to the bedside.

I learnt from this experience that the patient was totally unwilling to take in the horrible facts of his illness and was instead preoccupied with happy plans and thoughts of the future. In short, he preferred a fantasy of a happy future to the realities of death and dying.

I did not again attempt to tell an elderly patient the truth about a fatal illness, although I was always careful to inform the relatives. It would seem that many old people prefer to plan for a happy though unrealistic future rather than face a dismal fatal one. Many patients prefer to think about happy tomorrows as well as hope springing eternal. We should not take steps to change this unless patients ask directly for the truth for a good reason, which they seldom do.

A N G Clark emeritus consultant physician, Brighton Health District 